\title{
Vertically induced autokinesis
}

LEOHARD BROSGOLE AND ROBERT M. CRISTAL NAVAL TRAINING DEVICE CENTER
The egocentric location of a fixated visual stimulus was shifted away from the apparent eye level position by means of induced motion. When the stimulus appeared to be in the periphery, the inducing frame was occluded resulting in autokinesis toward the phenomenal level of the eyes. This effect, termed induced autokinesis, was not obtained in certain predicted instances. It was concluded that apparent egocentric displacement is sufficient for initiating autokinesis.

Laterally induced autokinesis was demonstrated by Brosgole (1967) in an attempt to relate visually perceived movement to egocentric spatial displacement. In essence, $S$ fixated a stationary luminous target, in total darkness, surrounded by a rectangular frame which moved from left to right, in one instance, and from right to left in another. As the frame displaced to the right, for example, the apparent median plane shifted along with it-inducing the target to move to the left. The frame was occluded upon reaching the end of its travel, permitting the subjective straight ahead to return back to true center. As a result, the target autokinetically drifted from its initial position on the left to a phenomenally straight ahead location. The opposite obtained when the frame journeyed to the left. Changing the location of a target relative to the apparent median plane, then, appeared to be sufficient for inducing autokinesis along a horizontal plane.

It may be contended that autokinesis was induced laterally simply because the horizontal dimension of space is not preferred. That is to say, the normal propensity to see autokinesis in an up-down direction would not be subject to the kind of experimental manipulation described above. The following, therefore, will deal with vertically induced autokinesis.

As opposed to the apparent median plane, which is fairly accurately estimated in total darkness, the subjective eye level generally tends to progressively drop over time, giving rise to upward autokinesis in the majority of cases (Glick, Wapner, \& Werner, 1965). Accordingly, if the apparent eye level were induced to fall prior to inspecting an isolated visual target, it would tend to maintain that spatial location over time, resulting in the target being seen as statically suspended overhead. If subjective eye level were induced to rise, on the other hand, it would rapidly descend during inspection to its normally lowered position, resulting in a marked upward autokinesis of the target. The reverse would obtain for those Ss who typically demonstrate a gradual rise in subjective eye level when placed in total darkness.
The following experiment was designed to test the above proposition using the induced autokinetic procedure.

\section{Apparatus}

The basic equipment has been described in greater detail elsewhere (Brosgole, 1967). It essentially consisted of a horizontally traveling screen (60 in. high $x 30$ in. wide) upon which stimuli could be mounted. The screen was driven back and forth along a set of tracks by a variable speed motor via a system of gears and pulleys. It journeyed 22 in. through space at a rate of $40^{\prime}$ of visual arc per sec. At the end of its 22-in. journey, the screen activated a relay reversing the motor and, as a result, its direction of travel. It was remotely operated by E. For purposes of this study, the entire apparatus was rotated by $90^{\circ}$ so as to enable the screen to travel vertically instead of horizontally.

Stimuli

The stimuli consisted of a 3/8-in. diameter circular spot of light surrounded by a 30-in. square frame with 1-1/8-in. wide borders. They were both constructed of Sylvania, white electroluminescent Tape-Lite which allowed their brightness to be regulated. The target was set at 1.8 and the frame at $.009 \mathrm{ft}-\mathrm{L}$. In addition, use of the Tape-Lite permitted them to be turned on and off independently in a prescribed fashion. Both the frame and spot were centered in the objective median plane with the dot 34 in. above the floor. The center of the frame varied from $45 \mathrm{in}$. to $23 \mathrm{in}$. above the floor as it traveled up and down.

\section{Procedure}

The experiment took place in total darkness with $S$ seated $10 \mathrm{ft}$. from the apparatus in a chair removed from the cockpit of a flight trainer. The height of the chair was adjusted so that eye level was 34 in. above the floor. The $S$ participated in three conditions.

In the first, $S$ viewed the target surrounded by the frame which moved upward from a central position. At the end of its upward excursion, the frame reversed direction and was automatically turned off until reaching its lower extreme, 15-1/2 sec. later. At that point, it again changed direction and was turned on as it began to ascend. The frame moved up and down three times in this manner with the target continuously visible.

The second condition was identical to the first, except that the frame was visible while moving downward instead of upward. In the third condition, $S$ viewed the target for $60 \mathrm{sec}$. in total darkness with no frame present. The $\mathrm{S}$ was instructed to fixate the target 
in each of the conditions and to ignore the frame at all times. He was required to provide a continuous running account of the direction of apparent target movement and was prompted to respond rapidly whenever necessary. The three conditions were varied among Ss.

\section{Subjects}

Three males and one female participated in this study. Ranging in age from 23-32, their mean age was 27.8 years.

\section{Results and Discussion}

Condition 3 served as a control, in that it furnished a means for determining the normally preferred direction of spontaneously initiated autokinesis and, by inference, the vector along which the apparent eye level tends to displace for a given $S$. In this condition, two Ss perceived upward autokinesis exclusively, indicating that the apparent eye level was continuously drifting downward. As a result, when the frame lowered the subjective eye level in Condition 2, the spot was induced to rise and it remained statically suspended overhead, even after the frame was switched off. The target was induced io fall when the frame shifted the phenomenal eye level position upward in Condition 1. As opposed to the prior treatment, where occlusion of the surround did not induce autokinesis, the spot now began to hastily ascend to a phenomenally elevated terminal position, along a direct vertical path, as soon as the frame was turned off.

One $\mathrm{S}$ saw predominantly downward motion in Condition 3, implying that the apparent eye level had shifted upward. As a result, when the frame was extinguished after lowering the subjective eye level in Condition 2, the spot dropped autokinetically at a rapid pace. Condition 1, on the other hand, did not yield the induced autokinetic effect.

The final $S$ perceived only lateral autokinesis in the control condition, signifying that the apparent eye level position was not affected by simply a lack of visual articulation. As a result, the two experimental treatments did not produce a differential induced autokinetic effect. The fact that there was as much upward as downward induced autokinesis, in this case, provided beautiful verification of our basic hypothesis.

In brief, whenever the inducing influence of the frame opposed the normal directional drift of the subjective eye level, autokinesis ensued. Autokinesis was not observed when the frame escalated such a shift.

It is obvious, then, that autokinesis can be induced vertically as well as horizontally. We may conclude that varying the location of a target relative to the apparent eye level position is sufficient for generating autokinesis along the vertical dimension of visual space.

\section{References}

Brosgole, L. Induced autokinesi s. Percept. \& Psychophys., 1967, 2, 69-73.

Glick, J. A., Wapner, S., \& wemer, H. Some relations between autokinetic motion and space localization. Acta Psychol., 1965, $24,41-48$. 